\title{
Buscar en la ausencia. Lo 'soviético’ en los cuentos y las identidades cubanas
}

Seeking into Absence. Soviet Influence in Cuban storys and identities

\section{CAROLA HeINRICH}

Academia Austríaca de Ciencias · Carola.Heinrich@assoc.oeaw.ac.at

Realizó sus estudios de Filología Románica en la Ludwig-Maximilians-Universität de Munich (Alemania) y en la Universidad de La Habana (Cuba). Desde 2011 efectúa sus estudios de doctorado en la Universidad de Viena y desde 2012 está asociada al Instituto de Estudios Culturales e Historia del Teatro de la Academia Austríaca de Ciencias. Algunas de sus publicaciones relevantes son "Entre el despeje y la nostalgia. La subjetividad pos-soviética en el cine cubano" (2013) y "Siguiendo la pista de los rusos: Der postsowjetische Film in Kuba" (2014).

RECIBIDO: 4 DE FEBRERO DE 2015

ACEPTADO: 3 DE JUNIO DE 2015

Resumen: Durante más de tres décadas, la Unión Soviética penetró en todas las esferas de la vida cubana. A pesar de ese largo período de intercambio, lo soviético no aparecía en la producción literaria más que en contadas ocasiones. Sólo después de la caída del campo socialista despierta la memoria de aquella compleja etapa histórica. El análisis trata las huellas que dejaron la Unión Soviética y su derrumbe en la sociedad cubana y en la identidad de sus miembros por medio de su manifestación en los cuentos contemporáneos escritos a partir de los años noventa. La representación de ‘lo soviético’ y de ‘lo cubano', de 'lo ajeno' y de 'lo propio' se examina con respecto al contenido y a una particular estilística y estrategia literaria. A efectos de la teoría poscolonial, se interpreta el significado que sigue teniendo la Unión Soviética para los constructos identitarios.

Palabras Clave: Cuba, URSS, cuento, estrategia literaria, identidad.

\begin{abstract}
While the Soviets influenced all political, economic and social spheres in Cuba during the 30 years of collaboration. Despite this long period of cultural exchange, the Soviet barely appeared in the Cuban cultural production. Only after the Soviet breakup did Cuban literature start to reflect upon this complex historical epoch. This paper studies Cuban short stories written after 1989. The object of investigation is the depiction of 'the Russian' as a representative of the Soviet Union and as a contrast to the Cuban population. The opposition between 'the self' and 'the other' will be analyzed regarding content and literary style and strategy. The impact of the Soviet Union on identity construction as the former hegemonic power and its expression in contemporary short stories will be analyzed and interpreted.
\end{abstract}

Key Words: Cuba, Postcolonialism, Soviet Union, short stories.

DOI: 10.7203/KAM.5.4598 
Durante más de tres décadas la Unión Soviética estuvo omnipresente y penetró en muchas esferas de la vida cubana. Un gran número de cubanos estudió ruso, muchos viajaron a la Unión Soviética ya para realizar estudios universitarios, formación profesional o simplemente por cuestiones de trabajo; otros regresaron con su conyuge soviético o son hijos de parejas cubano-soviéticas (Puñales-Apízar, 2010: 3). La cultura soviética dejó sus huellas en la sociedad cubana a través de dibujos animados soviéticos, programas de radio, obras literarias y revistas, películas y series televisivas, y estuvo presente en la vida cotidiana a través de los juguetes infantiles, la leche en polvo o las frutas enlatadas (ibíd.). Aunque la perspectiva soviética penetró todas las categorías sociales del país, sin embargo, era muy común escuchar hasta años muy recientes que los 'rusos' no dejaron nada luego de su abandono de la Isla (Yoss, 2004: 138). El siguiente análisis tratará de encontrar las huellas que dejó la Unión Soviética y su derrumbe en la sociedad cubana, así como de interpretar la influencia y significación de lo soviético para la construcción de la identidad cubana, por medio de la comparación de la representación de ‘lo soviético’ y ‘lo cubano', del Otro y de lo propio, en el cuento cubano contemporáneo a partir de los años noventa.

Metodológicamente se aplicará la teoría poscolonial, basada en el concepto de la alteridad que se debe esencialmente a la obra Orientalism (1991) de Edward Said, y que consiste en un discurso autoafirmativo de diferenciación del otro. Mientras Said enfoca la relación colonial del mundo arabíco con Europa y los Estados Unidos, esta publicación mira hacia el Este, hacia la antigua 'madrecita Rusia', y considera la Unión Soviética como un poder hegemónico y poscolonial. Para Said la identidad cultural se constituye a partir de la consciencia de alteridad, es decir, mediante la contraposición contrastiva del Otro. Esas imágenes, estructuradas binariamente, de ‘lo propio’ y 'lo ajeno’ tienen un carácter constructivo y culturalmente productivo. Esta oposición se amplía por el concepto de la hibridez, desarrollado por Homi Bhabha (1994) que acentúa los diversos y muchas veces contradictorios entrelazamientos entre identidad y alteridad, y que esquiva de esta manera la autoridad del discurso hegemónico. Por la constante confrontación con la cultura dominante se produce una hibridez dinámica que hace posible un tercero, que crea algo nuevo más allá de la estructura existente de ‘lo propio’ y del Otro: el así llamado tercer espacio, del estar culturalmente en medio, de poner en contacto y promover el diálogo entre diferentes tradiciones, a veces incompatibles, y renegociar de este modo conceptos establecidos de etnicidad, de género, de nación o generación. Esa excavación de un tercero deconstruye oposiciones polares y delibera espacios intermedios, híbridos. De esta manera se distingue del proceso 
de la transculturación ${ }^{1}$, con el que Fernando Ortiz (1973) describe la formación de la identidad cubana, por no basarse en la diversidad cultural, sino en la diferencia cultural. En vez de afirmar solamente la pluralidad, pone de relieve la ambivalencia de culturas, es decir, que no se trata del acercamiento a un consenso cultural que fomenta la formación de una identidad, sino de un proceso inconcluso de negociación y readscripción mediante el entrecruzamiento de discursos diferentes y muchas veces contradictorios. De esta forma, no se analiza la identidad sino las diferencias culturales (BachmannMedick, 2009: 197-198). El análisis se lleva a cabo por medio de la representación del personaje del Otro con el objetivo de encontrar estos espacios híbridos en la literatura y de qué manera específica se manifiestan en los textos literarios, sea en cuánto al contenido o a estratégicas narrativas, analizadas a base de los conceptos narrativos de Genette (2007).

Como consecuencia de las estrechas relaciones y el intercambio entre la extinta Unión Soviética y Cuba, era muy frecuente ver en Cuba personas de descendencia de los países socialistas europeos, muchas veces llamados 'rusos' de manera genérica: estudiantes, trabajadores o parejas siguiendo al esposo de vuelta en su patria. Muchos de ellos regresan a su país después de la caída del campo socialista europeo, debido a la dura situación económica, problemas familiares, interculturales o sencillamente porque terminaron sus estudios o servicios de trabajo. Paradójicamente, en este caso la aparición del personaje 'ruso' en la narrativa no sucede como correlato de la realidad inmediata. Como personaje, aparece solo después del derrumbe de la Unión Soviética, en el mismo momento en que desaparece de nuevo de la vida cotidiana cubana. Los escritores cubanos enfrentan su presencia de manera marcadamente diferenciadora solo a través de su desaparición.

Las carencias del oficialmente denominado 'período especial en tiempos de paz’ paralizan la actividad editorial durante la década de los noventa. Por falta de papel, las editoriales privilegiaron los cuentos y la poesía e imprimieron libros de pequeño formato y plaquetes. Cuentos aislados se divulgaron en publicaciones periódicas y antologías, y se desarolló una nueva generación de cuentistas cubanos que pone en duda la herencia cultural modélica, renovando el género sea temática o estilísticamente (Capote, 2008: 636-637). Estas condiciones editoriales y literarias constituyen una razón decisiva para la determinación de los cuentos como base de este análisis. Odette Casamayor Cisneros argumenta que "perseguir la imagen de Cuba en la obra de sus narradores equivale a renunciar a la búsqueda de un

${ }^{1}$ En su tratado del Contrapunteo cubano del tabaco y el azúcar introduce un nuevo vocablo técnico, el término transculturación. El neologismo expresa el proceso recíproco a través del cual dos o más culturas entran en comunicación en un territorio dado y llegan a fusionarse formando otra cualitativamente diferente de las que le dieron origen, producto de una síntesis de muchos elementos humanos dispares, desarraigados de una cultura precedente y puestos en contacto en un mismo tiempo y espacio geográfico. Una cultura que es como una suma de factores provenientes de diversas zonas y que allí se han unido para formar algo nuevo, distinto, propio (Ortiz, 1973: 134-135). 
Carola Heinrich. Buscar en la ausencia...

concepto único y definitivo de la Isla" (2002: 36) debido a la multiplicidad de voces y expresiones y la diferencia que las caracteriza. No obstante este análisis estudia las diferentes manifestaciones de la construcción de la identidad cubana en confrontación con 'lo soviético' en los cuentos cubanos a partir de los años noventa, ejemplificado por cuatro cuentos escogidos, y trata de deducir una posible estética pos-soviética.

\section{El Otro cubano: "He visto pasar los trenes", de Obdulio Fenelo Noda}

El largo período de intercambio y colaboración sufre un descenso ya años antes del derrumbe de la Unión Soviética. El partido comunista cubano rechazó el proceso de reformas iniciado en la URSS por Mijaíl Gorbachov en 1985. Como consecuencia, las autoridades cubanas empezaron a filtrar y censurar ideológicamente el pensamiento soviético que llegaba a la Isla, con el fin de conservar el propio poder (Rojas, 2007). Por muchos años, las traducciones al español de las editoriales soviéticas Mir, Raduga y Progreso constituyeron las fuentes literarias más importantes, así como las solicitadas revistas informativas rusas Sputnik, Misha y Novedades de Moscú (Heredero, 2011). Las revistas se prohibieron por la divulgación y apoyo de la glasnost y la perestroika, y 10000 estudiantes y trabajadores cubanos residentes en los países socialistas de Europa del Este recibieron la orden de regreso inmediato (Loss y Prieto, 2012: 22). Especialmente a partir de 1992, las relaciones con la extinta Unión Soviética pasaron a ser una herencia incómoda, un tabú del pasado inmediato:

Entre 1986 y 1989, durante los tres años decisivos de la perestroika y la glasnost, se produjo una radical inversión del campo referencial soviético en la cultura cubana: de ser un lugar metropolitano y paradigmático, fuente de valores y lenguajes de legitimación, Moscú pasó a ser bruscamente, una ciudad subversiva, disidente, exportadora de ideas y gustos desestabilizadores para el socialismo cubano. (Rojas, 2007)

Mientras en las tres décadas anteriores se adaptaron los modelos, técnicas e ideales del hermano mayor, en ocasiones hasta obligatoriamente, ahora se condenaban. Se censuraron los medios, la unión económica se disolvió y poco a poco desaparecieron las mercancías rusas y el apoyo económico, que más tarde serían sustituidos por las importaciones chinas (Rodríguez, 2012: 51). Con el fin de conservar el poder y el sistema político Cuba reniega del parentesco cubano-soviético y, con una especie de reideologización, destaca la propia singularidad (Ferrer, 2012: 97-99). Esto se expresa de modo oficial con el cambio de la referencia al leninismo-marxista por las teorías del héroe nacional cubano José Martí y la cancelación en 1992 del párrafo refiriéndose a 'la hermandad con la Unión Soviética', presente en la constitución cubana (Loss, 2009: 106). Por ende, recurrir al tema soviético no significa sólo narrar la 
pérdida y revitalizar un mundo que ya no existe, sino también romper un tabú, excavar algo reprimido y olvidado oficialmente.

El tema de la pérdida y del olvido forzado está presente en la representación del regreso: después de haber estudiado en la URSS, los cubanos llegan por una parte cambiados por la experiencia ajena, pero también a una sociedad diferente y desconocida, tal y como sucede en el cuento "He visto pasar los trenes" (2006), de Obdulio Fenelo Noda. Se trata de una experiencia que comparten muchos cubanos y que Obdulio Fenelo Noda narra a través de la historia de Beltrán Dubois, un hombre que ha estudiado en Kiev, Ucrania. Este personaje está en desigual combate con la extrañeza, lo foráneo, la desfiguración de la memoria y el contacto permanente con otra realidad durante el período especial. Se introduce pues, un cuestionamiento del modo en que es manejada la cuestión de la identidad cuando esta se encuentra en un conflicto de elección entre valores de dos culturas opuestas, y de qué forma resulta expresada en la narrativa. Es un cuento ambientado en Cuba, en cuya realidad irrumpe ahora un cubano, el cual parece no encajar más en la vida dejada atrás. No solo se distingue físicamente por la ropa que lleva, sino que se aborda también la cuestión de cuánto se ha asimilado o no al ambiente soviético y qué consecuencias trae para su propia autodefinición. Se distinguen dos oposiciones binarias culturales cuya expresión se busca en el relato: por un lado, las diferencias entre los cubanos residentes en la Isla y el que regresa, pero por otro lado una oposición interna de este último, quien confronta a su retorno a una vieja forma de sí mismo contenida en las memorias y expectativas de la gente, una oposición entre la persona que era antes de irse y la que es ahora, influenciado por su experiencia soviética y confrontado con el nuevo alrededor.

Beltrán Dubois, mientras estudió en Kiev, se casó y tuvo una hija con una ucraniana, Galina. Pero cuando él decide regresar a vivir a Cuba, Galina lo abandona y retorna con la hija a su pueblo natal. Beltrán intenta buscarlas, pero no lo dejan verlas y así debe regresar a Cuba solo, sin volver a ver a su hija Oxzana. De regreso en Cuba, no logra olvidar ni reintegrarse a la sociedad. Se refugia en la memoria y vive obsesionado con tomar el tren al pueblito donde vive su hija.

Beltrán es descrito "sentado en la cama, fumando su pipa azul, vestido de traje sin corbata", con "la maleta sobre la silla" (Fenelo Noda, 2006: 339) y se siente el "olor a colonia fresca, a ropa lavada" (ibíd.). "Saca el peine y comienza a acicalarse el pelo, el bigote, la barba añeja y escasa. Guarda la pipa azul" (ibíd.: 344) y está listo para irse. "El traje prusia, la colonia, la maleta y el relato trillado [ya han anunciado] nuevamente la crisis" (ibíd.: 343). Es solo una sombra de la persona que era una vez. El "Beltrán anterior a 1989, el de la ciudad que sube, negro ilustrado, diestro en idiomas" (ibíd.: 341), "antes, fue un negro importante" (ibíd.: 344), pero ahora no lo es más, es incapaz de volver a vivir su vida. Antes "fue gracioso verlo probarse trajes invernales, reírse a carcajadas mientras sobreactuaba a un cosaco, con su pipa azul y el abrigo extravagante en el clima del trópico" (ibíd.: 340). Lo que antes era un 
Carola Heinrich. Buscar en la ausencia...

chiste se convirtió en una triste realidad. Ahora luce ridículo en su "traje prusia, hecho a la medida del Beltrán anterior a 1989” (ibíd.: 341).

Esta oposición entre quien era antes y el que está desde hace "once años esperando junto a su maleta, dispuesto a partir todos los días del mundo" (ibíd.: 340), es enfatizada por una oposición entre silencio y ruido, por un contraste espacial entre su propio mundo imaginado y el mundo de afuera, la realidad cubana. "Han transcurrido once años y, aunque lo ha intentado, desde hace meses no se atreve a dar un paso fuera de estas cuatro paredes" (ibíd.), así que ni "reconoce la ciudad que sube y sale al paso" (ibíd.: 344). Allí se construye su mundo cerrado y quedan fuera "el gentío, las quejas ante la falta de luz artificial en la noche cerrada, las maldiciones contra el país, las ganas de morirse de algunos, de matar" (ibíd.: 339-340). Representa un lugar de ensoñación en el que quiere estar para escapar de "este solar superpoblado, repleto de voces y gritos, de seres incapaces de buscar su sitio verdadero” (ibíd.: 339), luchando para sobrevivir contra las dificultades que tienen que confrontar cotidianamente, y "aunque las voces disminuyen y la gente comienza a recogerse, se respira el temor, la zozobra de lo por venir" (ibíd.: 342). Y mientras "se escuchan llantos de niños, gritos de madres”, Beltrán "se tapa los oídos" (ibíd.: 342). El bullicio del solar se opone al silencio en su mundo aislado, representado de forma marcadamente ficticia. "Es posible que no escuche o finja el silencio" (ibíd.: 339), no osa hablar, solo susurra, pero "nada tiene de habitual el silencio en este solar superpoblado, [...] no es real este silencio" (ibíd.). Parece una película inventada, el intento de atrapar un momento irreal, como si alguien est[uviera] filmando esta secuencia [...] como fotografiados” (ibíd.: 339). El tiempo parece detenerse, y "las palabras, como extraviadas, se quedan rondando en la habitación, a la espera” (ibíd.: 340).

Vive en un sueño, un sueño en el que huye, al que se aferra y en el que no quiere dejarse sucumbir. Es una utopía, un mundo irreal, la ilusión de una vida mejor y no quiere aceptar que no se haga realidad. Reconstruye esta ilusión "seductor: Europa la nueva, la roja, la justa, la de los pobres con honor, la de la nieve y El capital’ (ibíd.). Es la utopía de una Unión Soviética que ahora parece patética e irónica y que desde hace muchos años ya no existe. Son también once años de su amigo, el Yo narrador, "dedicados a alimentar la ilusión” (ibíd.), a “correr a comprar medio litro de alcohol puro e inventar [su] porción de vodka” (ibíd.: 339), “a seguir el juego [...] de verdades y mentiras a medias” (ibíd.: 340). Lo traiciona, es la reproducción de algo que en realidad nunca existió, se trata de mantener una ilusión, "un secreto siempre a punto de quebrarse" (ibíd.). El protagonista llora por este paraíso perdido, "le corre una gota de lágrima” (ibíd.: 339) por esta utopía soviética perdida, por esta visión de un futuro cubano que no va a cumplirse, por esta esperanza en la que creyó una vez, antes de que "el avión terminó tragándolo y [empezó] a flotar, rumbo al paraíso, donde todos somos iguales” (ibíd.: 341), un paraíso que no existe, una ilusión de la URSS que en realidad lo decepcionó, lo discriminó por su raza: 
Carola Heinrich. Buscar en la ausencia...

En el tren, un niño mira asombrado a la madre y le anuncia que en el vagón hay un abisyána, es decir, un mono del tamaño de un hombre. [...] Nunca podría vivir en su país, África es una tierra de salvajes [...] todos los negros vienen de África y allí la civilización no ha llegado (ibíd.: 339-340)

Es una huída ante la decadencia moral y la dura situación económica, ante la pérdida de ideales. Es una fuga hacia un pasado, un refugio simbólico de la memoria, en tanto no es capaz de reconocer y vivir la realidad, vive encerrado, aislado, fuera de su propia vida: "No puede olvidar, no quiere" (ibíd.: 341), porque solo sosteniendo esta realidad fingida, creyendo en que existe, es capaz de estar contento, "y lo veo reír [...], esquivando una lágrima, a punto de ser feliz” (ibíd.: 345).

\section{Yo y la rusa: "Clemencia bajo el sol", de Adelaida Fernández de Juan, y "El tartamudo y la rusa”, de José Manuel Prieto}

En muchos casos la situación era diferente a la planteada en el cuento anterior: los cubanos regresaron y trajeron consigo a sus parejas. Cuando Julio Cid enumera los principales aspectos de la influencia soviética durante los treinta años de intercambio, pone énfasis además de en el apoyo técnico y en los estudiantes cubanos, en las mujeres soviéticas que se casaron con ellos y que vinieron a Cuba (2010: 53).

El tratamiento del tema de la emigración soviética llegó retrasado no solo al campo de la literatura, sino también al mundo científico. Dimitri Prieto Samsonov, investigador del Instituto Cubano de Antropología, se ocupa en particular de la situación de la comunidad soviética en Cuba y de las "huellas culturales rusas y de Europa del Este en Cuba”, título también de un panel de discusión organizado por la revista Temas. Allí pone de relieve el hecho de que sin duda existe una gran minoría soviética en Cuba, pero esta no se percibe como una comunidad porque está compuesta por miembros de los diferentes países socialistas europeos, sean rusos, ucranianos, bielorrusos, letones, búlgaros o hasta húngaros y alemanes, que ahora son representados por las instituciones de los diferentes estados (ibíd.: 52).

No existen datos exactos sobre el número de personas soviéticas que vive en Cuba hoy en día; los cálculos oscilan entre 2000 a 5000 (Wieser, 2006: 54), 3000 (Prieto Samsonov y Martínez Shvietsova, 2008: 138) y hasta 10000 de personas (Sequera, 2000). La minoría ex-soviética se distingue de otras minorías sobre todo por los motivos de su emigración. Durante las más de tres décadas de colaboración intensa llegaron 10000 técnicos, militares y asesores a Cuba. En el año 1990 vivían alrededor de 18 000 soviéticos en la Isla, sin contar los militares (Heredero, 2011). Pero la mayoría de ellos dejó el país

al expirar sus contractos de trabajo o, más tarde, con el derrumbe de la Unión Soviética. En el 2006, 
Carola Heinrich. Buscar en la ausencia...

Isabella Wieser, de la Universidad de Viena, estudió desde una perspectiva sociolingüística la comunidad rusohablante en la Habana. Sus investigaciones indican que el 99 por ciento de la primera generación de migrantes soviéticos fueron mujeres, que conocieron a sus parejas cubanas en su patria y y vinieron con ellos a la Isla. En consecuencia, habla de una inmigración matrimonial (Wieser, 2006: 53).

Las relaciones entre mujeres cubanas y hombres soviéticos fueron más raras. Eso no quiere decir que no existieron, pero fueron escasamente públicas u oficializadas por casamiento. Jacqueline Loss trata de explicar este hecho por razones de una jerarquía implícita: mientras que las mujeres soviéticas eran consideradas bellezas deseables, los hombres ocupaban altos cargos políticos o militares o representaban el poder tecnológico, de modo que eran símbolos de la hegemonía y de la adaptación forzada del modelo soviético que eran rechazadas en Cuba (Loss, 2012: 184). Por lo tanto, el tratamiento de la figura soviética en la producción cultural cubana comprende casi solamente personajes femeninos, con la excepción de Sobre Sovexportfilm, de Rubén Rodríguez, y la película Lisanka, de Daniel Díaz Torres.

En los siguientes cuentos se aborda el asunto de la confrontación matrimonial entre estas dos culturas tan distintas, tan lejanas, y sus consecuencias, que se manifiestan en la vida familiar muchas veces problemática. Llegados a Cuba, estas diferencias destruyen el matrimonio una vez feliz, tal y como sucede en el cuento "Clemencia bajo el sol" $(2002)^{2}$, de Adelaida Fernández de Juan, donde el encuentro con la cultura ajena produce conflictos, engaño e infidelidad. Tematiza la retirada de las personas soviéticas que llevaban muchos años de residencia en Cuba a comienzos de los 90, en este caso, la mujer rusa. Adelaida Fernández de Juan pone el énfasis aquí en la condición de la mujer, en sus temores, pero también en los esquemas sociales que la limitan y en la solidaridad mediante la cual llega a superarlos (Capote, 2008: 644).

El cuento nos narra la historia de una cubana que mata por el honor de una rusa. La rusa, Ekaterina, llega a vivir con su esposo cubano, Reyes, en un solar de Centro Habana. Ella y Cuqui, la vecina, desde cuya perspectiva se cuenta la historia, hacen amistad a pesar de las diferencias y dificultades culturales que tienen que confrontar. Pero el matrimonio no funciona, y como tantas otras esposas rusas se marcha con el hijo y vuelve a su país. La amiga, Cuqui, quiere castigar a Mireya, la querida de Reyes, y

\footnotetext{
${ }^{2}$ En su libro Dreaming in Russian, Jacqueline Loss analiza con detalle la obra literaria de, entre otros autores, Adelaida Fernández de Juan, Polina Martínez Shvietsova, José Manuel Prieto y Anna Lidia Vega Serova. En particular, al abordar "Clemencia bajo el sol" Jacqueline Loss abunda en el proceso de "cross fertilization" de los dos personajes y en la categorización de la añoranza de lo ruso por parte de Cuqui. Uno de los argumentos esenciales de Dreaming in Russia, un volumen seminal en la categorización y definición de este tema de estudio, es precisamente el modo en que estos procesos de hibridación ruso-cubana se han concretado en la literatura contemporánea.
} 
Carola Heinrich. Buscar en la ausencia...

la mata por rabia en el parque de enfrente, cuando Mireya vende las últimas cosas que quedaron de su amiga Ekaterina.

La historia es contada desde la perspectiva de Cuqui, con focalización interna, lo cual implica que incorpora también sus valoraciones y normas del habla cubana, como representante de los cubanos en general. Empieza por presentarse y cuenta qué pasó en forma de testimonio en la estación de la policía, la confesión de un asesinato. Más que un monólogo, se trata de un diálogo implícito con el destinatario o participante externo al texto. Este se manifiesta en preguntas implícitas y observaciones de un posible policía que se muestra aparentemente impaciente, pero que nunca aparece en el relato. Cuqui dirige la palabra directamente al lector como si él la interrogara, y responde a preguntas que nunca están escritas en el texto, pero que el lector añade e incorpora automáticamente por la reacción demostrada. El personaje se declara culpable y empieza a contar cómo conoció a Ekaterina, la historia de su amistad, para hacernos entender por qué mató a Mireya.

Cuando se vieron por primera vez, no podía haber nada más opuesto. La vio no solo distinta, sino también con una marca negativa. Le

pareció insoportable, estirada, era una rusa de la cabeza a los pies, tan blanca que dejaba pasar el sol por sus ojos con el pelo rubio, medio enredado y era delgada como una caña tierna, y para colmo venía preñada. Parecía un fideo con un nudo en el centro. Lucía orgullosa, respingada, y entró en el pasillo sin saludar, hasta molesta. (Fernández de Juan, 2002: 78)

Cuqui describe a 'la rusa' en contraste con el Yo, con ella misma, y además contrapone a 'la rusa' a 'nosotros', los cubanos. Cuando el esposo de Ekaterina, Reyes, contrariamente a ella, “empezó a repartir besos y abrazos" (ibíd.) le habla a un lector supuestamente cubano: "Imagínese, usted sabe cómo somos nosotros, por más que le pese, usted también debe ser así" (ibíd.). Pues aunque no les guste a los cubanos, es su manera colectiva de actuar, es un conjunto de conducta nacional, la construcción consciente de una identidad cubana aunque sea indeseada.

Más allá de los rasgos físicos la diferencia de Ekaterina consite en su timidez, pasividad y miedo: "se puso de pie [...], a la defensiva, como hacen las gallinas cuando una perra olfatea la jaula" (ibíd.), "era inteligente" (ibíd.), pero "estaba desesperada, pobrecita" (ibíd.). Cuqui, al contrario, es representada de manera activa, toma la iniciativa, aunque impulsada por "la curiosidad [que] puede más que la decencia" (ibíd.): "Le extendió el plato y sonrió, con sus veintiséis años de mulata, y ella la dejó pasar. [...] Ella puso el dulce encima de la mesa y le tomó las manos" (ibíd.). Es una criolla divertida, aunque consciente de que no conoce mucho del mundo, que nunca ha "salido más allá del túnel de La 
Carola Heinrich. Buscar en la ausencia...

Habana" (ibíd.: 79); sin embargo es fuerte, se las arregla en la vida porque sabe luchar para sobrevivir y nunca se muerde la lengua, porque no tiene "pelos en la lengua ni horchata en las venas" (ibíd.: 82).

Esta oposición entre lo frágil, lo débil por un lado, y el carácter tenaz, autónomo e independiente por otro, se demuestra claramente en dos situaciones.

Primero en sus opiniones en cuanto a los hombres. De un lado la sexualidad, un asunto que Cuqui tematiza abiertamente, sin pena, incluso llega a ofrecer consejos: "cuando te acuestes con él tienes que decirle Papi riquísimo, me vuelves loca" (ibíd.: 83). Se afirma el prejuicio de los cubanos apasionados, que gritan su excitación. Ekaterina, al contrario, es recatada, "ella se reía y se reía y se ruborizaba como una niña” (ibíd.), pero no logra salir de su timidez, solo se ríe nerviosamente. Para Ekaterina su esposo era un Rey, el nombre mismo, Reyes, revela esta relación. "Decía: Gusta mucho, Rey. Ella le decía Rey, y se ponía una corona de aire en la cabeza. Claro que entendió. Para ella era como un rey” (ibíd.: 79). La reacción de Cuqui es mucho más dura: "Yo le dije: No, Ekaterina, todos hombres ser cabrones, ser diablos" (ibíd.). Cuqui lo ve con desencanto y claridad, y es también ella quien reconoce el peligro que emana de Mireya y le advierte a Ekaterina: "Me dio mala espina desde que la vi. Llamé aparte a Ekaterina y le dije: No es buena, no la dejes estar aquí en el cuarto. ¿Por qué, Cuqui? Haz lo que te digo, rusa, y no preguntes tanto" (ibíd.: 81). Ella es suspicaz y rigurosa, pero demuestra un buen conocimiento de las personas, porque su presentimiento se hace realidad(“y entonces supe que se había acostado con él”, ibíd.: 82). Ekaterina, en cambio, es ingenua, confiada y bondadosa. Esta oposición también lleva al trágico final del cuento, al asesinato, porque mientras Ekaterina es cerrada en sus emociones, no quiere vengarse y no quiere herir a nadie, Cuqui no puede detenerse, aunque quiera:

Yo soporté todo aquello en silencio, me repetí muchas veces que no era asunto mío, más me dolía la tristeza de Miguel que la alegría de Reyes, pero usted comprenderá que no me era fácil [...], pero traté de tranquilizar mi encabronamiento repitiéndome que no era problema mío (ibíd.: 84)

Es de sangre caliente y "lo único que quería era castigarla como se merecía la muy puta” (ibíd.: $85)$.

La segunda situación, dejando claro la oposición antinómica, es el parto. Ekaterina llama en busca de ayuda a su amiga cuando empiezan las contracciones: “ ¡Cuqui, venir, venir! Fue como Ekaterina gritó cuando se puso de parto" (ibíd.: 80). Cuqui acude en su auxilio y la lleva al hospital donde su hijo "Volodia nació flaco y transparente como su madre" (ibíd.). Ekaterina se lo agradece "llorando [...] diciéndole: spasiva Cuqui, spasiva. [...] Dice su tío que eso se llama el alma rusa” (ibíd.). La mención del tío lleva a la observación de un nivel subjetivo y personal, a un nivel colectivo y nacional, una superposición general de los cubanos sobre los rusos. Ella se encuentra desamparada con una profunda 
Carola Heinrich. Buscar en la ausencia...

tristeza en el alma, pero Cuqui, en cambio, sabe manejar bien la situación ella sola, "iba sola al hospital. Miguel fue un tronco desde el primer día, tragón, grande y hermoso como su padre” (ibíd.).

La oposición se repite en la fisonomía de los hijos. Pero poco a poco se van disolviendo las diferencias entre las dos culturas. En el caso de las madres con una lenta aproximación a la otra cultura, desconocida y siempre valorada más bien de forma negativa, así que Cuqui empieza a leer la literatura rusa y cambia su opinión y estimación.

Todo empezó cuando ella consiguió libros traducidos para ayudarse en su trabajo, y me animó a leerlos. Yo le advertí que no resultaría, que yo no llegaba ni al final de los periódicos, pero ella insistió tanto que empecé. Óigame, yo creía que los hombres rusos eran toscos y brutos como los osos, con los dedos cuadrados y los muslos fofos de no usarlos como es debido, hasta que leí Ana Karenina. ¡Válgame Dios! Eso sí es una novela, no las de la televisión. (ibíd.)

Ekaterina adopta también elementos típicamente cubanos: "La única visita que tuve fue la de Ekaterina [...] con un termo de té y un pozuelo de arroz con leche, no sabía si echarme a reír o llorar. ¿Quién ha visto a una rusa haciendo dulces criollos?” (ibíd.: 80). Aún cuando luce un poco ridícula, pero esa ridiculez se trasforma en normalidad mediante la incorporación de elementos de la cultura ajena simbolizada por componentes típicos en la generación de los hijos, que "crecieron juntos, [...] que Miguel tiene delirio con el té, y Volodia, [...] debe seguir enviciado con el café carretero" (ibíd.). No se trata de una verdadera mezcla, pero se verifica un cambio de posicionamiento de los sujetos que se manifiesta ya sea en las madres o en los hijos. No es posible, a partir de este momento, hablar de dos culturas, como categorías claramente definidas y opuestas. Estas se reconocen en el Yo, en los sujetos representados, ya sea desde la perspectiva cubana o desde la rusa, a partir de elementos consustanciales al Otro. En la oposición, sea tan fuerte como sea, los contrarios se influyen recíprocamente y el Otro empieza a formar parte del Yo también.

Cuando "Reyes y Ekaterina vinieron a vivir en el cuarto de al lado cuando él terminó de estudiar en Rusia" (ibíd.: 77) trajeron un parte de Rusia consigo, no solo las tradiciones y costumbres que constituyen su carácter y mentalidad, sino también cosas materiales, “porque Reyes y Ekaterina trajeron todo de Rusia, parece que para hacerse la idea de que seguirían viviendo allá” (ibíd.: 78). Los personajes crean un mundo propio ficticio, intentando preservar el pasado, crear una realidad fingida. Pero "figúrese usted, con tanta bulla, tanto calor y tantas moscas, ¿cómo iban a lograrlo? Pero bueno, de eso se encargó el tiempo" (ibíd.). No solo los sujetos se confrontan como opuestos, sino que también el ambiente parece incompatible y descompone despiadadamente la ilusión que habían creado: 
Carola Heinrich. Buscar en la ausencia...

Las cosas que habían comprado se fueron destiñendo en el cuarto, y ella se ponía furiosa con cada cucharón de madera que se partía, con los relojes en forma de llave del Kremlin que se detenían, cansados para siempre, oxidados por el salitre, y sobre todo cuando se despegó la foto inmensa de la catedral de San Basilio, que los niños usaron para papalotes. (ibíd.: 81-82)

Su recreación ficticia de la vida en Rusia se está deshaciendo. "Pobre Ekaterina. No eran solo sus cosas las que se desmoronaban" (ibíd.: 82). La ilusión rusa construida por la pareja desapareció poco a poco, igual que su amor, y al parecer no quedó nada más, de modo que, ella también se va. Se va y se lleva a su hijo, como "todo lo ruso se fue" (ibíd.: 83). Con el derrumbe de la Unión Soviética se fueron también todas las cosas soviéticas, materiales o ideológicas, que durante tantos años inundaron la Isla. Los cubanos siempre dijeron "que las cosas rusas eran una mierda. [...] Estaban tan acostumbrados a los relojes de pulsera que pesaban una tonelada y a los zapatos que parecían de ladrillo que, cuando de pronto desaparecieron, no sabían qué hacer” (ibíd.: 82). Los productos rusos siempre eran malos y negativos, pero ahora que ya no los tenían, sumado a la difícil situación económica durante el período especial, los recuerdan positivamente, porque aunque eran malos, eran mejor que lo que tienen ahora:

¿Y qué me dice de la carne enlatada? No, no voy a bajar la voz, yo no tengo pelos en la lengua ni horchata en las venas, mucha hambre que matamos con la carne rusa y con las manzanas de pomo. Es verdad que sabían a rayo encendido, pero ¿ahora qué? Ahora ni trueno ni rayo ni la madre que los parió. (ibíd.)

Era una especie de revaloración tardía, de nostalgia por las cosas rusas, provocada por su desaparición repentina. Aunque antes no se las quería, ahora se las desea de vuelta, se siente un extrañamiento y un tipo de dolor, "viendo cómo se evaporaban los recuerdos, una parte de mi vida" (ibíd.: 84). La cultura rusa, material y espiritual, dejó inesperadamente su huella en los sujetos, en forma de una costumbre y una historia colectiva que lleva a esta nostalgia y al sentimiento de pérdida que se manifiesta también en la actitud de las personas: “Todo lo ruso se fue. Ya estoy cansada de lo que viene y se va. [...] Ya ve, yo también lloro, y eso que no tengo el alma rusa que dice mi tío” (ibíd.: 83). Las cosas rusas dejan de llegar y muchos rusos regresaron, pero aunque todo se fue, algo quedó. Aunque a los cubanos les guste afirmar que los rusos no dejaron ninguna huella, estos los influyeron y dejaron algo que está ahí, aunque no lo quieran. El hecho es tematizado y simbolizado por los muebles rusos que, aunque se han marchado sus propietarios, todavía llevan el leve olor ruso que se queda, por mucho que quieran deshacerse de ellos.

No habían pasado ni tres meses cuando Mireya llegó y se instaló en el cuarto de Reyes [...]. Empezó por hacer una limpieza general, y fue sacando uno a uno los muebles para el pasillo, y los restregaba con un cepillo así grande, y tiraba agua y más agua, pero qué va, el olor de Ekaterina y 
Carola Heinrich. Buscar en la ausencia...

de Volodia estaba allí todavía, y a una le parecía que en cualquier momento iban a aparecerse por atrás de la puerta pidiendo café acabado de colar. (ibíd.: 83-84)

Mientras en el cuento de Adelaida Fernández de Juan las identidades son atravesadas lentamente por la historia, influyéndose recíprocamente y reblandeciendo las fronteras que las separan, en "El tartamudo y la rusa" (2002), de José Manuel Prieto, somos engañados, por contra, por las oposiciones binarias que se afirman constantemente y resultan finalmente relativizadas por el discurso.

El cuento se inicia con un discurso autorreflexivo, en forma de introducción al relato, como una guía de cómo se escribe una buena historia. Parece un ensayo teórico sobre la naturaleza intertextual de los textos, con anotaciones, mencionando las referencias a las que remite. También en los capítulos siguientes se marcan claramente las referencias mediante notas. Las fronteras entre ensayo crítico y cuento ficticio se difuminan. A continuación, se cuenta en cuatro capítulos la historia "de un hombre que una noche lo confundió con su hermano mayor, médico de profesión" (Prieto, 2002: 89), y le "pidió ayuda, facultativa para su esposa y espiritual para él” (ibíd.). Es la historia del tartamudo Jorge Torres quien, tras asistir a unos cursos en la URSS, conoce a Elena, una bella mujer rusa con "la piel suave de sus manos, el brillo de sus ojos y de su pelo rojo" (ibíd.: 93), de la cual se enamora y a quien lleva consigo a Cuba. Pero el matrimonio degenera en violencia, causada por las diferencias culturales.

El personaje se describe a sí mismo (y por extensión a los cubanos) de modo peyorativo, porque no es capaz de controlarse, pierde "los estribos" (ibíd.: 100), es celoso, demasiado apremiante, así que "al empuje de [su] vehemencia iban cayendo uno tras otro los tabiques que la separaban de [él]" (ibíd.), y obsesionado con ella era "incapaz de percibir otra cosa que no fuera ella" (ibíd.) hasta el punto de ser posesivo, desatento e ignorante: "La escuchaba sin tomarla mucho en cuenta. Muy enamorado, [...], pero sin interesarse por la primera vez que ella había visto el mar, ni por nada que no fuera saber que hoy estaba sentado frente a ella" (ibíd.: 98). De este modo se describe Jorge Torres a sí mismo, en un discurso directo referido por el narrador, la conversación con el supuesto médico, en la que siempre se asegura que el de enfrente y todos (los cubanos) actuarían de aquella forma:

Estoy seguro de que Ud. tampoco podría, y conozco a pocos hombres capaces de hacerlo. (ibíd.: 103)

Jorge Torres me miró fijamente a los ojos a través del humo del cigarro para ver la impresión que esta parte del relato causaría en mí. Yo debía saltar intrigado y aventurar una suposición de esa índole: “¿Lo había estado engañando?” o bien: “¿Qué hacía esa mujer encerrada con aquel hombre cuando Ud. no estaba?”. (ibíd.: 99) 
Carola Heinrich. Buscar en la ausencia...

Pero el Yo narrador rompe esa ilusión de una identidad cubana cerrada, o mejor, de macho cubano, mediante la constatación de que “Torres esperó en vano la pregunta” (ibíd.: 99).

Para él, los cubanos son incapaces de amar abnegadamente, al contrario de las rusas, quienes sufren, se sacrifican, hasta encuentran placer en este sacrificio: "Ella me había tomado como objeto de su servidumbre y era feliz sirviéndome” (ibíd.: 104). Él la admira e insiste en que ella era "tan buena! [...] "de una virtud ejemplar"” (ibíd.: 100) y comprensiva. "Una mujer muy bella, de una belleza que sugería esplendidez y no frivolidad ni perfidia" (ibíd.: 98), que él no la merecía, que "no era el hombre que le convenía" (ibíd.: 105). Elena es descrita minuciosamente, como la imagen de una Santa, se le convierte casi en una mártir, aún cuando se le muestre como una mujer pasiva, cuando él le ha "estado pegando como media hora y ella sin decir palabra...” (ibíd.: 91). Es reservada, no "dijo nada, ni gritó de alegría, ni hizo un gesto" (ibíd.: 103) cuando le pidió la mano, es “una mujer demasiado frágil” (ibíd.) e indefensa.

Pero esa entrega total, esa comprensión total que no objetaba nada me desconcertaba. Como si con su inteligencia de mujer hubiese dado con la verdad de las mártires. Nunca me reprochaba los días y las noches idas en refriegas y discusiones. Para ella esa era su vida y no tenía sentido eludirla. (ibíd.)

Pero exactamente esa servidumbre lo desespera, “mientras más hacía por [él], más le pegaba”, (ibíd.), lo provoca y causa su agresividad porque no reacciona, no se defiende, no lo reprocha.

El cuento parece afirmar una identidad nacional, que no cambia aunque uno quiera. Y aunque hay influencias desde afuera, la oposición no resulta relativizada, sino que se mantiene inamovible hasta el final. Pero se tiene que tener en cuenta que todos estos atributos, esta oposición construida es contada directamente por Jorge Torres, una intranarración metadiegética, casi siempre desde su perspectiva como Yo narrativo ficticio, en forma de discurso directo, a veces marcado, a veces no, explicando sus pensamientos y emociones con focalización interna o relatando desde el supuesto rol del médico. Es una narración dentro de la narración; tenemos pues dos niveles narrativos: la historia de amor entre Jorge Torres y Elena en forma de narración intradiegética, relatada por Jorge como narrador homodiegético; y la conversación entre el Yo y Jorge Torres, mientras Elena está durmiendo en la sala, una narración extradiegética. Esa segunda narración tiene la función de una trama que sirve de marco para el relato de Jorge Torres. Aquí, el Yo narrador homodiegético, el aparente médico de quién desconocemos el nombre, nos refiere esta conversación posteriormente, de nuevo mediante una focalización interna, situándola en el contexto de un diálogo en el que pocas veces muestra una reacción o plantea una pregunta, dejando a su interlocutor relatar su historia. 
Carola Heinrich. Buscar en la ausencia...

A estos dos niveles narrativos se añade un tercero, un tipo de metatexto constituido por la introducción antes mencionada y las notas a pie de página. Resumiendo, tenemos una narración en tres planos, uno insertado en el otro, como para utilizar una metáfora del imaginario soviético, las muñequitas de la matrioska.

En este último, el metatexto, el autor implícito se distancia del texto, primero por tomar una perspectiva editorial, dejando claro que se trata de una historia que "oí de labios de un hombre" (ibíd.: 89), que solamente va a relatar y que “contaré sin trampas, sin ocultar nada” (ibíd.). Una afirmación contradictoria, irónica que no se tiene que tomar demasiado en serio, porque en segundo lugar comenta críticamente el texto, su propio cuento, mediante un discurso autorreflexivo en el que explica exactamente su estrategia narrativa y los métodos estilísticos para contar los hechos, lo cual implica siempre una falsificación y una transformación de la historia. Explica con detalle los procedimientos utilizados para redactar el texto y expone la técnica a demostrar en el cuento:

Digo que la contaré sin trampas porque quiero exponer el modelo que me conformé y tratar de hacer ver al lector qué paralelos encontré en mi memoria para determinados episodios a medida que iba escuchando y tiempo después por obra de pensar en ello. Esas llamadas que calzan el texto son como las fuentes de este trabajo y para ampliarlo habría que acudir a ellas. (ibíd.)

Tal y como se ha descrito, en el texto se marcan las intertextualidades y el narrador explica sus procedimientos: "3En realidad no me especificó la altitud. He tomado el dato de una novela policial, Muerte en las nubes, de Agatha Christie" (ibíd.: 91). Pero este también se expresa críticamente en cuanto a la narración intradiegética, dudando de su veracidad, "99 Al oírle decir esto pens[ó] que no había ocurrido en realidad y ahora Jorge lo imaginaba" (ibíd.: 100). Al final de la introducción anuncia que "La historia de amor, el tratamiento dramático también aparecerán, pero ya limpio de disquisiciones teóricas. A partir de aquí este es un cuento como cualquier otro" (ibíd.: 89), pero otra vez pone al lector sobre la falsa pista, porque en la narración extradiegética aplica un procedimiento parecido. El Yo narrador se distancia del cuento de Jorge Torres, toma una perspectiva desde afuera, comentando, poniendo en duda la veracidad de su relato, porque "no parece que el marido le hubiese pegado mucho como dijo: no descubr[e] hematomas grandes ni enrojecimientos, más bien parece un desmayo provocado por la tensión nerviosa” (ibíd.: 91), y lo corrige que “mejor hubiera dicho ‘de una virtud ejemplar’ y esa hubiera sido la frase exacta" (ibíd.: 100). A través de este discurso autorreflexivo nos hace dudar de la fiabilidad del narrador interno, Jorge Torres y, además, del presunto autor del cuento y sus explicaciones en la introducción. Sobre todo, pone de relieve el carácter ficticio de la narración, pero esto no solo en la narración extradiegética, sino que identifica también a Jorge Torres claramente como narrador de una 
historia ficticia. Lo hace no solo por dudar de la veracidad, sino por demostrar que él también emplea métodos narrativos.

$\mathrm{Al}$ darse cuenta de que su interlocutor pierde el interés por la historia, que le "daba igual [...] y le continuaba oyendo más bien por cortesía” ( ibíd.: 97) intenta capturar su atención y dice "en un susurro, como para abrirle el apetito: 'Le voy a contar algo realmente extraordinario, algo sobre lo que nunca oyó hablar"” (ibíd.). El narrador pone al descubierto las estructuras y estrategias narrativas de Jorge Torres también:

Torres esperó en vano la pregunta y aquello terminó por agradarle. Yo no habría entendido nada de haber formulado tal pregunta, me habría quedado tras el primero de los círculos concéntricos de su relato. Esa pregunta, tal conjetura, estaba excluida. ¡Qué fácil todo si se hubiera podido encontrar una pregunta así, una conjetura así para esta historia! (ibíd.: 99-100)

Parece que el receptor, su interlocutor, le descubre el juego, y complace al narrador, a Jorge Torres, al entender la historia en un nivel más profundo. Se trata del llamado lector cómplice, en este caso un oyente cómplice, y este pasa su conocimiento al lector. Pero al final parece que no lo entiende:

- No tiene por qué sentir pena de haberme contado todo eso, quiero que sepa...

- ¿Pena? -me replicó Torres sonriendo-. ¿Pena?

$[\ldots]$

Antes de perderse por la esquina, ella volvió su rostro hacia mí y sonrió. [...]

- ¿Pena? -me había dicho Jorge Torres-. ¿Pena por qué? (ibíd.: 106)

Quiere preguntar: ¿por qué sentir pena?, ¿por haber contado una historia? Es una historia ficticia, no tiene por qué sentir pena por haberla contado. El foco no está en la historia, sino en contarla, no en la historia, sino en el discurso.

La intertextualidad y la autorreflexividad provocan un distanciamiento del texto y son métodos típicos para enfatizar el carácter ficticio del mismo. Se pone en duda la veracidad de la historia y así también se relativizan los constructos identitarios expuestos, se les declara como ficticios, deformados, distanciados y falseados por las estrategias y técnicas aplicadas, sujetos a la voluntad del autor. 
Carola Heinrich. Buscar en la ausencia...

\section{Entre yo y yo: "Proyecto para un mural conmemorativo (Técnica mixta)", de Ana Lidia Vega Serova}

Pero estas mujeres no constituyen la última generación de soviéticos en Cuba, sino que trajeron consigo el fruto de estas relaciones. "Además de las decenas de miles de cubanos que fueron a la Unión Soviética, están los tantos miles [...], que regresaron trayendo un pedazo de la cultura rusa en forma de esposas, en forma de hijos - a las cuales en Cuba se les dice 'agua tibia' - que se convirtieron en puentes culturales: demasiado rusos para ser completamente cubanos, demasiado cubanos para ser completamente rusos" afirma Yoss (Temas, 2010: 55). El etnólogo cubano Fernando Ortiz utilizó la metáfora del ajiaco cubano para simbolizar la composición de la identidad cubana. ${ }^{3}$ Prieto Samsonov y Martínez Shvietsova le añaden a esta cazuela abierta un ingrediente más: la segunda generación de la diáspora (post-) soviética en Cuba, los hijos de las parejas cubano-soviéticas (2008: 138). A ese grupo a menudo lo llaman equivocadamente rusos, pero "no eran ni rusos, ni cubanos, ni agua fría ni caliente, sino agua tibia" (Yoss, 2004: 140), el modo de que se denominan también a sí mismos, 'agua tibia' o 'polovinas's.

Estos hijos de matrimonios mixtos crecieron en ambientes familiares bilingües y asumen una posición muy afectiva frente a su país de origen (Wieser, 2006: 175). Lo que sorprende es que según las investigaciones de Isabell Wieser la mayoría entre ellos se denomina a sí misma como rusos en vez de cubanos y que el deseo de regresar es más fuerte en esta segunda generación (ibíd.: 176). Se debe tener en consideración que el deseo de dejar a Cuba atrás y empezar de nuevo en otro país radica también en el descontento con la difícil situación económica y social presente, y la emigración representa para muchos jóvenes cubanos la única posibilidad de prosperidad, hecho que relativiza este deseo de regreso. Zeta Dacosta, por su parte, no comparte los resultados de Wieser, sino que constata que los polovinos “raramente emplean el término Madre-Patria para denominar a Rusia [...] La mayoría de los que viven en Cuba se asumen como cubanos por decisión y convicción" (Dacosta, 2009: 26). El sentimiento de pertenencia es muy subjetivo y difícil de mesurar. Algunos entre ellos expresan esta experiencia personal por medio de la cultura, como Ana Lidia Vega Serova, nacida en el entonces Leningrado. Una narradora dividida entre dos culturas y dos lenguas que da una imagen de ese desgarro interior a través de sus

\footnotetext{
3“La imagen del ajiaco criollo nos simboliza bien la formación del pueblo cubano.

Sigamos la metáfora. Ante todo una cazuela abierta. Esa es Cuba, la isla, la olla puesta al fuego de los trópicos [...] Ahí van las sustancias de los más diversos géneros y procedencias” (Ortiz, 1974: 39-40).

${ }^{4}$ Polovina significa 'medio' en ruso, seguido por la terminación del plural española. 
Carola Heinrich. Buscar en la ausencia...

cuentos y novelas. En su relato "Proyecto para un mural conmemorativo (Técnica mixta)" (2010), se tematiza la división entre dos países, dos casas y el hecho de sentirse constantemente ajena.

El cuento está dividido en 39 párrafos, numerados y separados marcadamente, que conforman los trozos de cuatro historias que se desenvuelven paralelamente. Las cuatro historias se desarrollan en lugares y tiempos diversos y parecen haber sido entremezcladas arbitrariamente, hasta que el lector logra al final situarlas en el contexto adecuado e interrelacionarlas. Ya en el título se enuncia su técnica narrativa, una reunión de fragmentos mixtos y entrelazados por repeticiones. La autora se distancia, ofreciéndole la información al lector solo poco a poco, sin abandonar su perspectiva autoral y preservando el control sobre el relato, jugando con el conocimiento que el lector posee de la historia.

El cuento se inicia con la descripción de una extraña, una Otra, una "mujer con los audífonos puestos, parecida a una extraterrestre" (Vega Serova, 2010: 18). Nunca llegamos a saber su nombre, siempre la describirá con esa misma frase, repitiéndola siempre que aparece el personaje, marcado explícitamente por la palabra "extraterrestre" (ibíd.) como ajena. Gracias a los audífonos, se desconecta y aísla del mundo que la rodea y se refugia en su propio mundo de "fosforescentes soles y animales y algunos paisajes primitivos", que pinta "mecánicamente, casi a ciegas" (ibíd.) "sobre cartulinas estrictamente rectangulares”, mientras escucha llorando "canciones en un idioma extranjero" (ibíd.). No está pintando conscientemente, está casi en trance, en otro mundo, y llora por este; pero no queda claro si llora por el lugar que está pintando, por la lengua que está escuchando o por ambos a la vez. La ambigüedad del personaje se manifiesta a través del contraste entre el paisaje colorido, ingenuo, alegre y las lágrimas y la forma estrictamente rectangular de la carta que, visualizada de esta manera, demuestra su carácter estricto y disciplinado.

Avanzando con el cuento el lector se percata del motivo de la ambigüedad del personaje. La mujer extraterrestre es la misma de otro intrarrelato, en el que conocemos la historia de amor de sus padres, la madre rusa, "una mujer fascinada” (ibíd.: 19) y el padre cubano, "un hombre negro y alto" (ibíd.). Tampoco ellos son descritos de forma detallada, ni siquiera sabemos sus nombres. Los personajes del cuento son reducidos a unos pocos adjetivos, son estilizados mediante roles simbólicos, a menudo peyorativos, como máscaras vacías, dejándole al lector la facultad de llenarlas con vida. Personajes universales, que son un prototipo representativo para muchos que comparten esa misma historia. Así que no sorprende que los padres, aunque querían crear "un ser bello y sublime, algo así como un extraterrestre [...] la engendraban a [ella] [...] un embrión patético" (ibíd.: 19). Pero a fin de cuentas la trasformaron en extraterrestre, porque reducido al producto de un acto sexual, sus padres llevaron "al patético fruto de la fornicación muy lejos de la miserable ciudad de los puentes, tras los siete mares a una isla” (ibíd.). Sin embargo, cuando la mamá se marcha de nuevo tras el engaño de su marido, "arrancó de 
raíz a su hija arrancada de raíz con la intensión [sic!] de sembrarla en cualquier otro lugar” (ibíd.). El Yo que cuenta se define a sí mismo como una entidad ajena, arrancada de raíz en ambos mundos, extraterrestre en el sentido original y simple de la palabra, como algo que no forma parte de ninguna tierra. Sus raíces solo pueden crecer en su propio interior. "De sus orejas para fuera crecen los audífonos y cables. De sus orejas para dentro crecen las raíces arrancadas" (ibíd.). Y termina con la pregunta retórica: “¿A quién se le ocurriría que la mujer con los audífonos puestos, parecida a un extraterrestre puede ser un extraterrestre?” (ibíd.: 20).

La ambigüedad de su carácter queda demostrada por el ambiente, por la antinomia entre las dos tierras. Por un lado Rusia, Leningrado, "la ciudad de los puentes, la ciudad tísica de los puentes, la ciudad gris y pantanosa de los puentes" (ibíd.: 18). "Entre tantos puentes antiguos [...] en la podrida ciudad de los puentes [...] nevaba" (ibíd.: 19). Sus padres la llevaron "muy lejos de la miserable ciudad de los puentes, tras los siete mares, a una isla que podría llamarse desierta si no fuera por sus animales y soles y algunos millones de habitantes" (ibíd.). La hija "arrancada de raíz de la ciudad nebulosa de los puentes" (ibíd.) aprende a amar la nueva casa, "la isla de paisajes primitivos: en la isla no nevaba. [...] Quizá se nubló el cielo. [...] Cuanto más, llovió. Pero no nevó” (ibíd.). Esta fuerte diferencia entre Leningrado y Cuba utilizada en la descripción opuesta del ambiente, refleja las dos partes de su alma, de su identidad. Mientras Cuba es descrita como una isla exótica, alegre y fascinante por su originalidad y su salvajismo, la descripción de Leningrado tiene una connotación sombría, melancólica y triste, con colores borrados por la niebla y la nieve.

Pero al mismo tiempo deja claro que estos lugares antagónicos existen solo en su memoria, son ficticios, porque cuando la hija anuncia a su madre el regreso a Cuba, la idea "de volver a casa [...] la isla de paisajes primitivos que encontró [...] no era la misma isla de paisajes primitivos que podría llamarse desierta si no fuera por sus animales y soles y algunos millones de habitantes" (ibíd.: 20). En este momento la llama casa, pero se pregunta “¿A cuál CASA?”, “Existe un lugar llamado CASA?” (ibíd.) La respuesta la había dado al principio:

Es posible que exista algún lugar llamado CASA. Una puerta con la que juguetea el aire. Muy a lo lejos. Hombres con barbas oscuras y mujeres con pañuelos en las cabezas. Pan negro y té. Canciones en un idioma extranjero. Es posible que no exista. (ibíd.: 18)

Pero son solo recuerdos lejanos, irreales, algo que ya no existe, que está solamente en sus sueños, que son "imágenes de otros tiempos y lugares, soñados" (ibíd.: 20). Es algo en el pasado, pero lo experimenta como algo negativo, es un sueño de "melodías raras, palabras ambiguas en un idioma extranjero, una puerta con la que juguetea el aire, pesadillas, pesadillas" (ibíd.: 19). Siente inquietud por 
Carola Heinrich. Buscar en la ausencia...

lo que dejó atrás, aquello que vive solo en su memoria, algo marcadamente irreal. Es un lugar lejano e incierto, pero la "inquietaría mucho más" (ibíd.: 20), le daría miedo, si deviene realidad, algo tangible. "Sentiría mareos. Una puerta con la que juguetea el aire. Muy a lo lejos. Una melodía rara. ¿Una nana?" (ibíd.).

A través de la ensoñación de los dos lugares antagónicos, de las dos tierras perdidas, la narradora deja claro que no viene ni de una, ni de otra, que no puede llamar casa a ninguno de esos espacios y que por fin no cabe en ninguno de los dos, es un ser en medio, una extraterrestre. En ella siguen vivas las dos partes, aunque solo recordadas vagamente, no se puede asociar solamente a una de las dos.

Al mismo tiempo afirma que esta ambigüedad es algo negativo, algo inferior, algo que está mal. Porque la mujer escuchando "la voz del hombre en los audífonos pronuncia[r] frases musicales sencillas en el idioma extranjero [...] llora al reconocer palabras con significados ambiguos” (ibíd.: 19). "Sus lágrimas opacan la fosforescencia de los colores, diluyen los contornos, le infieren a las figuras significados ambiguos” (ibíd.). Las líneas y colores se trasforman, se difuminan, se encubren por las lágrimas y "surgen figuras abstractas y difusas que podrían recordar rostros de hombres con barbas oscuras y mujeres con pañuelos en las cabezas, imágenes de otros tiempos y lugares, soñados” (ibíd.: 20). Son recuerdos que se expresan en la pintura, inesperados. Deja claro que escribe desde Cuba, que es la imagen dominante, y Rusia es el "allá” (ibíd.: 18), que ya le parece tan lejos que apenas lo recuerda. No se siente como si volviera a allá, sino como si fuera por primera vez ("No, le dije a Fernan, no pienso por ahora ir allá. A lo mejor hasta le dije: no, no pienso volver allá” (ibíd.: 19). Pero no se deja borrar completamente y reluce bajo la superficie cubana. En estas "cartulinas estrictamente rectangulares" (ibíd.: 20) se abre un nuevo espacio, donde coexisten los dos mundos, un tercer espacio que disuelve la oposición binaria y representa su alma dividida.

Y esta la comparte con otros, como por ejemplo con "Fernan (Andrés Mir) [quien] es un buen tipo, poeta y socio. Viene a menudo a [su] casa, toma[n] té, habla[n]. Pero la razón por la que lo met[ió] en este cuento es que los dos naci[eron] en Rusia y él lo entiende” (ibíd.: 18). En esta cita se expresan dos identidades colectivas que ya no son identidades nacionales, sino identidades de grupo que les unen. Por una parte les une la historia de la comunidad soviético-cubana que tienen en común y que lleva a un entendimiento más profundo, sin palabras, que no necesita explicaciones: "No le expliqué nada del miedo ni de las cartas que no llegan ni de la nana. Pero él la oyó. Estoy segura de que él la oyó” (ibíd.: 19). Una solidaridad tan intensa que hasta le resulta chocante:

¿Para qué tendría que volver?, le respondí a Fernan.

No sé, dijo, allá está tu casa. 
Reí asustada tapando el vacío con la risa.

¿Existe un lugar llamado CASA?

(ibíd.: 20)

Se asusta porque él la copió, le descubrió el juego.

Por otro lado tematiza el acto de escribir y se distancia de este modo del texto. Mediante el discurso autorreferencial y la afirmación de que los dos son poetas, abre una nueva dimensión para la definición como autor que les une en un mismo grupo.

Reconoce en su infancia cubana la huella de un trauma, en su caso, las cartulinas, que son apenas un síntoma concreto de ese trauma. En ellas se expresa la necesidad de recuperar la infancia perdida, dejada al otro lado del mar, o quizás, en las dos tierras divididas por los siete mares, porque ambas están perdidas, existen solo en su memoria y las deja revivir en las cartulinas que pinta. Es posible entender la manía por las cartulinas, que han marcado su infancia y adolescencia, enviadas por su padre desde Cuba y ahora esperándolas desde el otro lado del mar, como añoranza por su infancia pasada. Por otra parte, se pueden interpretar como síntoma a través del cual se diferencia del resto de los cubanos y hay solo unos pocos que comparten su historia y la entienden. Refleja su condición de estar en medio a través de una poética casi seca, impasible y negativa, marcada por repeticiones y estigmatizaciones, que acude a una presentación satírica de los personajes, tratando de olvidar y negar su pasado ruso, convenciéndonos de lo agobiante que era. Pero no lo logra, porque, aunque le da miedo y la inquieta, no puede esconder que allá se encuentra el único lugar que alguna vez representó para ella algo parecido a una casa, como comprende su amigo, y aunque quiera nunca lo podrá negar o borrar, siempre formará parte de su alma. El personaje conserva algo de ambos padres y culturas, pero al mismo tiempo siempre es distinta de cada uno de los dos. No obstante, no se trata de un proceso de transculturación tal y como lo describe Fernando Ortiz. Sufre la pérdida de una cultura precedente, pero es desarraigada de nuevo sin que se cree una nueva realidad compuesta e integral. No se trata de la disolución armónica de los conflictos culturales, sino de una diferencia cultural valorada negativamente, un incómodo estar en medio, un entrecruce.

\section{Ensoñar, aceptar y alienar}

Las más de tres décadas de intensa colaboración e intercambio entre Cuba y la URSS dejaron no solo objetos y huellas visibles en esta isla caribeña, como nombres, dispositivos o carros, sino que influyeron a partir de la educación, formación y convivencia en la construcción de la memoria colectiva y la identidad cubana. A partir de los 90, cuando deja de existir la Unión Soviética, esta subjetividad 
florece en la literatura cubana, no solo como huella temática, sino también como una estética. Para los jóvenes narradores aquí vistos, las experiencias compartidas y los referentes soviético-socialistas comunes, que marcaron su infancia y la etapa de educación y formación, no solo integran una memoria colectiva, sino que también tienen un sentido generacionalmente diferenciador, tal como subraya Maylin Machado (2010: 2). Cuando después del derrumbe del campo socialista europeo se marcharon los últimos militares y técnicos soviéticos, y con ellos también algunas de las mujeres que habían seguido a sus parejas hasta Cuba, los jóvenes cubanos "se vieron de pronto con las manos vacías/vaciadas y sin saber hacia dónde mirar” (Puñales-Apízar, 2010: 4). Se encontraron en medio de una escasez económica y en el vacío ideológico, y como consecuencia empezaron a preguntarse por las huellas dejadas. Los cuentos analizados se dirigen a ese imaginario compartido desde ángulos diversos.

En "He visto pasar los trenes", Obdulio Fenelo Noda vuelve desde la añoranza de un paraíso perdido. La memoria encierra una armonía perdida a través de la cual se huye de las dificultades y la soledad del presente. "Clemencia bajo el sol”, de Adelaida Fernández de Juan, y "El tartamudo y la rusa”, de José Manuel Prieto, se acercan al tema de la diferencia, afirmando reiteradamente la oposición entre los cubanos y los soviéticos a un nivel personal, que poco a poco se disuelve y se cuestiona, y conduce finalmente a una aceptación. Es un reconocimiento reticente de las huellas dejadas en el alma cubana y de lo soviético formando parte de lo propio. Ana Lidia Vega Serova añade a esa partición un tono negativo en su cuento "Proyecto para un mural conmemorativo". La división representa una carga que lleva a la alienación de sí misma, del yo. La construcción de una identidad nacional ya no parece posible y es sustituida por una identidad de grupo.

Aunque sean tan distintas las vías de aproximación, lo que les une es una poética compartida. Es una literatura a menudo en una línea fantástica, que describe la intimidad de los personajes, muchas veces por medio de la ensoñación, o de un nivel autorreflexivo, demostrando la voluntad antirrealista, alejada de lo coloquial, de la burla o la pelea cotidiana y circunstancial, tal como caracteriza Margarita Mateo Palmer una rama de la cuentística cubana (2005: 197). Esto no quiere decir que la convocación subjetiva y fabulada de lo soviético no pueda conllevar, también, una negativa a este pasado restrictivo, teniendo en cuenta su representación marcadamente ficticia e irreal, que deja claro que se trata de un pasado irrevocable, descrito de manera desfigurada. 


\section{Bibliografía primaria:}

Fenelo Noda, Obdulio (2006). "He visto pasar los trenes". Arango, Haydée (eda.) Maneras de narrar: Cuentos del Premio La Gaceta de Cuba (1993-2009). La Habana: Unión: 339-345.

Fernández de Juan, Adelaida (2002). “Clemencia bajo el sol”. Strausfeld, Michi (eda.) Nuevos narradores cubanos. Madrid: Siruela: 77-85.

Prieto, José Manuel (2002). “El tartamudo y la rusa”. Strausfeld, Michi (eda.) Nuevos narradores cubanos. Madrid: Siruela: 87-106.

Vega Serova, Ana Lidia. "Proyecto para un mural conmemorativo (Técnica mixta)". La Gaceta de Cuba 1 (2010): 18-20.

\section{Bibliografía secundaria:}

Bachmann-Medick, Doris (2009). Cultural Turns. Neuorientierungen in den Kulturwissenschaften. Reinbek bei Hamburg: Rowohlt.

Bhabha, Homi K. (1994). The Location of Culture. London/New York: Routledge.

Capote, Zaida (2008). "Panorama del cuento". Instituto de Literatura y Lingüística "José Antonio Portuondo Valdor" Historia de la literatura cubana: Tomo III: La Revolución (1959-1988). La Habana: Letras Cubanas: 636-649.

Casamayor Cisneros, Odette. "Cubanidades de un fin de siglo: O breve crónica de ciertos intentos narrativos por salvar u olvidar la cubanidad". La Gaceta de Cuba 6 (2002): 36-40.

Dacosta, Zeta. “El nuevo mestizaje: Las Polovinas”. Islas 4 (13) (2009): 23-28:

Ferrer, Jorge (2012). “Around the Sun: The Adventures of a Wayward Satellite”. Loss, Jacqueline y Prieto, José Manuel (eds.) Caviar with Rum: Cuba-USSR and the Post-Soviet Experience. New York: Palgrave Macmillan: 95-108.

Genette, Gérard (2007). Discours de récit. Paris: Éds. du Seuil.

Heredero, Liliet. “Las diez huellas soviéticas en Cuba”. BBC Mundo (2011). 
Carola Heinrich. Buscar en la ausencia...

Loss, Jacqueline (2009). "Wandering in Russian". Hernandez-Reguant, Ariana (eda.) Cuba in the Special Period: Culture and Ideology in the 1990s. New York: Palgrave Macmillan: 105-122.

Loss, Jacqueline (2012). “Persistent Matrioshkas”. Loss, Jacqueline y Prieto, José Manuel (eds.) Caviar with Rum: Cuba-USSR and the Post-Soviet Experience. New York: Palgrave Macmillan: 183-196.

Loss, Jacqueline y Prieto, José Manuel (eds.) (2012). Caviar with Rum: Cuba-USSR and the Post-Soviet Experience. New York: Palgrave Macmillan.

Loss, Jacqueline (2013). Dreaming in Russian. Austin: University of Texas Press.

Machado, Mailyn (ed.). "El imaginario pos-soviético o la nostalgia de Misha". La Gaceta de Cuba 1 (2010): 2 .

Mateo Palmer, Margarita (2005). "Los cuatro puntos cardinales son tres: el norte y el sur (Los cuentos de los Novísimos narradores cubanos)”. Mateo Palmer, Margarita Ella escribía poscrítica. La Habana: Letras Cubanas: 194-234.

Ortiz, Fernando (1973). Contrapunteo cubano del tabaco y el azúcar. Barcelona: Ariel.

Ortiz, Fernando (1974). Nuevo catauro de cubanismo. La Habana: Editorial de Ciencias Sociales.

Prieto, José Manuel (1996). Nunca antes habías visto el rojo. La Habana: Letras Cubanas.

Prieto Samsonov, Dimitri y Martínez Shvietsova, Polina (2012). “...so, Borscht Doesn't Mix into the Ajiaco? An Essay of Self-Ethnography on the Young Post-Soviet Diaspora in Cuba". Loss, Jacqueline y Prieto, José Manuel (eds.) Caviar with Rum: Cuba-USSR and the Post-Soviet Experience. New York: Palgrave Macmillan: 133-159.

Puñales-Apízar, Damaris. "Cuba soviética: el baile (casi) imposible de la polka y el guanguancó". $L a$ Gaceta de Cuba 1 (2010): 3-5.

Reyes, Dean Luis. “Arqueología de la nostalgia o de cómo aprendí a amar a Tío Stiopa”. La Gaceta de Cuba 1 (2010): 6-9.

Rodríguez, Reina María (2012). "Nostalgia”. Loss, Jacqueline y Prieto, José Manuel (eds.) Caviar with Rum: Cuba-USSR and the Post-Soviet Experience. New York: Palgrave Macmillan: 37-53.

Rojas, Rafael. “Souvenirs de una Habana soviética (fragmento)”. Penúltimos días (2007). 
Said, Edward (1991). Orientalism. London: Penguin.

Sequera, Vivian. “Los rusos llevan apacible vida en Cuba”. ElNuevo Heraldo (2000).

Temas (2010). "Huellas culturales rusas y de Europa del Este en Cuba”. Ulimo jueves. Los debates de Temas Vol. 4. La Habana: ICAIC/Temas: 50-69.

Wieser, Isabell (2006). Die russischsprachige Gemeinschaft in Kuba. Eine soziolinguistische Untersuchung am Beispiel Havanna (2005). Viena: Universidad de Viena (tesis de díploma).

Yoss (Gómez Sánchez, José Miguel). "Lo que dejaron los rusos”. Temas. Cultura, ideología, sociedad $37 / 38$ (2004): 138-144. 